often withered as time passed. At governmental policy and planning levels, if the problem of mental health remains unrecognised and unacknowledged, then there is little that can be achieved. However, if a commitment to the implementation of carefully constructed and targeted community-based interventions were possible, harnessing the rich tradition of community support (ubuntu) that persists in rural Africa, a transformation is viable. Hope for the new cohorts of older Africans rests on those brave policy-makers who acknowledge the need to allocate resources to mental health.

If, instead, African governments continue to fail to meet this challenge, there is little point in rehearsing the specifics of appropriate interventions. The intentions, guidelines and suggested interventions already exist in thick documents carefully constructed by numerous international experts (United Nations, 2002; Patel et al, 2007). African countries can still prepare to meet the challenge of increasing numbers of dependent older persons with mental illness, by training personnel and preparing adequate health service systems, before these problems reach overwhelming proportions. Health service improvement cannot be cost free, but the provision of appropriate community care services and the training of lay persons who could assist older persons in maintaining independent function for as long as possible would be a cost-effective starting point.

We do not need more good intentions; older Africans now deserve commitment and action.

\section{References}

Bongaarts, J. \& Zimmer, Z. (2002) Living arrangements of older adults in the developing world: an analysis of demographic and health survey household surveys. Journals of Gerontology Series B - Psychological Sciences and Social Sciences, 57, S145-S157.

Clausen, T., Wilson, A. O., Molebatsi, R. M., et al (2007) Diminished mental and physical function and lack of social support are associated with shorter survival in community dwelling older persons in Botswana. BMC Public Health, 7, 144.

Ferreira, M. (2008) Ageing policies in Africa. In Regional Dimensions of the Ageing Situation. United Nations Department of Economic and Social Affairs.

Gureje, O., Kola, L. \& Afolabi, E. (2007) Epidemiology of major depressive disorder in elderly Nigerians in the Ibadan Study of Ageing: a community-based survey. Lancet, 370, 957-964.

Hendrie, H. C., Ogunniyi, A., Hall, K. S., et al (2001) Incidence of dementia and Alzheimer disease in 2 communities: Yoruba residing in Ibadan, Nigeria, and African Americans residing in Indianapolis, Indiana. JAMA, 285, 739-747.

Levkoff, S. E., MacArthur, I. W. \& Bucknall, J. (1995) Elderly mental health in the developing world. Social Science and Medicine, 41, 983-1003.

Patel, V., Araya, R., Chatterjee, S., et al (2007) Treatment and prevention of mental disorders in low-income and middle-income countries. Lancet, 370, 991-1005.

Prince, M., Patel, V., Saxena, S., et al (2007) No health without mental health. Lancet, 370, 859-877.

Saxena, S., Thornicroft, G., Knapp, M., et al (2007) Resources for mental health: scarcity, inequity, and inefficiency. Lancet, 370, 878-889.

United Nations (2002) Report of the Second World Assembly on Ageing. United Nations.

\title{
Elderly people with mental illness in South-East Asia: rethinking a model of care
}

\author{
Kua Ee Heok MBBS MD FRCPsych
}

Department of Psychological Medicine, National University of Singapore, email pcmkeh@nus.edu.sg

\begin{abstract}
The report World Population Ageing 1950-2050 (United Nations, 2002) estimated that in 2005 there were 37.3 million elderly people (i.e. aged 65 years or more) in South-East Asia (a region incorporating Brunei, Cambodia, Indonesia, Laos, Malaysia, Myanmar, the Philippines, Singapore, Thailand and Vietnam). There are only a few epidemiological studies on mental disorders among elderly people in this region and the published data are mainly from Singapore, Malaysia and Thailand. Using Singapore's prevalence rate of 3\% for dementia and $5.7 \%$ for depression, the numbers of elderly people with dementia in this region would be 1.2 million and with depression 2.12 million (Kua, 1992; Kua \& Ko, 1995). However, even in Singapore, we have identified only $10 \%$ of all potential cases of dementia and depression - meaning that the large majority of elderly people with mental disorders are not detected, although they may be known, for other reasons, to the health services.
\end{abstract}

The under-diagnosis partly arises because most doctors are not taught geriatric psychiatry in the undergraduate curriculum, and even those with some training have difficulty recognising the early signs and symptoms. Medical students are often given clinical teaching in the context of a general hospital or mental hospital, where cases of dementia or depression are of moderate to severe degree. However, within primary care the clinical presentations are usually mild and may not yet fulfil the criteria (DSM or ICD) that apply to the diagnosis of more advanced disorders.

\section{Access to services}

In most South-East Asian countries there is a dearth of mental health services and human resources (Tasman et al, 2009). Unfortunately, the priority accorded to geriatric care is often low; geriatric psychiatry is never a popular 
subspecialty for mental health professionals, including psychiatrists and nurses.

Many elderly Asian people prefer to see traditional healers whenever they are unwell. Cultural perceptions of illness, and societal attitudes towards the elderly and family support, may explain such people's health-seeking behaviour ( $\mathrm{Ng}$ et al, 2004; Ma et al, 2009). Traditional healers are popular with the elderly not only because of the accessibility of their services but also because they share the same sociocultural beliefs about illness and health (Kua, 2004).

The focus of elderly mental healthcare should be in the community. Anchoring the service to a mental or general hospital generally leads to institutionalisation, sluggish bureaucracy and dislocation of family contact. There will inevitably be an associated stigma because of the mental institution, and an associated sense of anxiety concerning abandonment.

A day hospital or centre in the community can be the nucleus of a geriatric service in which doctors, nurses, psychologists and other mental health therapists work as a team. The Nottingham model, developed by Professor Tom Arie, has a combined geriatric medicine and geriatric psychiatry unit, which facilitates referrals, reduces costs and allows for integration of the two services. Having separate centres for geriatric psychiatry and geriatric medicine often leads to a duplication of services, the division of essential personnel like physiotherapists and nurses, and eventually to spiralling costs. Being in the community encourages referrals from primary care doctors. Elderly people are more motivated to go to the centres during the day and return home at night.

On the basis of accepting referrals of suitable geriatric patients from a general hospital, the day hospital or day centre can provide a step-down care programme, and this may reduce bed shortages in acute hospitals.

In Singapore there is tremendous support for such a service from voluntary organisations like religious groups, those representing retired persons and other charitable organisations. Galvanising community support is critical to ensure the success of mental health services for elderly people.

\section{Training and service provision}

There should be regular training workshops for staff working with these groups and educational programmes for the public to promote preventive psychiatry, to identify early symptoms and to de-stigmatise mental illness.

It has been suggested that to assist primary care doctors in identifying dementia, a screening questionnaire like the Mini-Mental State Examination (MMSE; Folstein et al, 1975) can be helpful. However, the MMSE is lengthy (it takes some 20-30 minutes to complete). In most primary care clinics in South-East Asia, doctors have just 10-15 minutes per patient. The MMSE is also culturally and educationally biased. Based on research conducted by the World Health Organization (WHO), we have constructed a short instrument, the Elderly Cognitive Assessment Questionnaire (ECAQ), which is more appropriate for those elderly people who are less well educated (Kua \& Ko, 1992). The ECAQ can be administered in 10 minutes.

Of course, it is important for mental health services for elderly people to solicit feedback and evaluation. Such health service research will provide valuable information on how to improve future programmes.

An increased connectedness between mental health services, voluntary organisations and family carers has seen a gradual decline in suicide rates among elderly people in Singapore (Kua et al, 2003). In 1995, the suicide rate among the elderly Chinese population in Singapore was at an alltime high of about 60 per 100000 . We identified those at greatest risk, especially elderly people who were disabled and living alone. In teaching primary care doctors we informed them where they could refer these patients to for social service assistance or treatment. Prevention programmes were run by non-governmental organisations like the Gerontological Society. A telephone helpline was started by a voluntary group called the Singapore Action Group of Elders. The Department of Psychological Medicine in the National University of Singapore provided training for retired persons to act as peer counsellors. There were discussions with the health authorities, with the aim of creating more day centres - some of which were managed by religious organisations - and to have more training opportunities in geriatric psychiatry for doctors, nurses, social workers, psychologists and other therapists. Since 1995 the suicide rate in the elderly population has fallen gradually, to the present level of about 17 per 100000.

\section{Family support}

There is a growing concern about caring for an increasing number of frail elderly people in South-East Asia, not only because their number is increasing but also because there is a diminishing number of carers - traditionally, carers are the women in the family. The present concern emanates partly because of the social transformation of the Asian family. Young couples today prefer to live away from their parents. Women are better educated now and prefer to go out to work rather than to remain at home. Kua \& Tan (1997) studied 50 family carers of patients with dementia in Singapore and found $56 \%$ had symptoms of anxiety and depression.

With the global economic crisis, there may well be an increase in the number of elderly people with depression, since many are dependent on their families for financial support (Phua \& Kua, 2009).

\section{The future}

Care for the frail elderly population in South-East Asia will continue to rest on the family for the foreseeable future. Carers need to seek help outside the home. Support networks typically have the family at their core but should also include friends, neighbours and home-helps. Community and governmental supports are necessary to alleviate the burden on the family. Although there are only a few old people's homes and day centres in most Asian countries, families may not be eager to use them because to send an elderly relative to such services implies a rejection of responsibility. However, with the change in family structures, many carers may have to turn to the community services in caring for their elderly relatives. 
To ensure the detection of early or mild disorders, training of medical students should include work at primary care clinics. In the forthcoming new editions of ICD and DSM, the criteria for diagnoses must include mild disorders. Early diagnosis and a comprehensive management plan will improve the quality of life of elderly people with mental illness.

\section{References}

Folstein, M. F., Folstein, S. E. \& McHugh, P. R. (1975) 'Mini-Mental State'. A practical method for grading the cognitive state of patients for the clinician. Journal of Psychiatric Research, 12, 189-198.

Kua, E. H. (1992) A community study of mental disorders in elderly Singaporean Chinese using the GMS-AGECAT package. Australian and New Zealand Journal of Psychiatry, 26, 502-506.

Kua, E. H. (2004) Focus on psychiatry in Singapore. British Journal of Psychiatry, 185, 79-82.

Kua, E. H. \& Ko, S. M. (1992) A questionnaire to screen for cognitive impairment among elderly people in developing countries. Acta Psychiatrica Scandinavica, 85, 119-122.
Kua, E. H. \& Ko, S. M. (1995) Prevalence of dementia among elderly Chinese and Malay residents of Singapore. International Psychogeriatrics, 7, 439-446.

Kua, E. H. \& Tan, S. L. (1997) Stress of caregivers of dementia patients in the Singapore Chinese family. International Journal of Geriatric Psychiatry, 12, 466-469.

Kua, E. H., Ko, S. M. \& Ng, T. P. (2003) Recent trends in elderly suicide rates in a multi-ethnic Asian city. International Journal of Geriatric Psychiatry, 18, 533-536.

Ma, S., Kua, E. H. \& Ng, T. P. (2009) Determinants of mental health service use in the national mental health survey of the elderly in Singapore. Clinical Practice and Epidemiology in Mental Health, 50, 2.

Ng, T. P., Tan, C. H. \& Kua, E. H. (2004) The use of Chinese herbal medicines and their correlates in Chinese older adults: the Singapore Chinese longitudinal study. Age and Ageing, 33, 135-142.

Phua, K. H. \& Kua, E. H. (2009) The economic crisis and mental health services in Asia. Asia-Pacific Psychiatry, 1, 55-57.

Tasman, A., Sartorius, N. \& Saraceno, B. (2009) Addressing mental health resource deficiencies in Pacific Rim countries. Asia-Pacific Psychiatry, 1, 3-8.

United Nations (2002) World Population Ageing 1950-2050. Population Division, DESA, United Nations.

\section{Mental healthcare in Hungary: contradictions and possibilities}

\section{Tamás Kurimay MD PhD}

President, Hungarian Psychiatric Association, Director of Psychiatry, Department Chair, Saint John Hospital and North-Buda Integrated Hospitals, Budapest, Hungary, email tamas.kurimay@janoskorhaz.hu

\begin{abstract}
$T^{\text {he }}$ he Republic of Hungary is a landlocked country of $93000 \mathrm{~km}^{2}$ in central Europe; it is bordered by Austria, Slovakia, Ukraine, Romania, Serbia, Croatia and Slovenia. Its official language is Hungarian. Hungary joined the European Union (EU) in 2004. About $90 \%$ of the population of c. 10 million is ethnically Hungarian, with Roma comprising the largest minority population (6-8\%). Currently classified as a middle-income country with a gross domestic product (GDP) of $\$ 191.7$ billion (2007 figure), Hungary's total health spending accounted for $7.4 \%$ of GDP in 2007, less than the average of $8.9 \%$ among member states of the Organisation for Economic Co-operation and Development (OECD, 2009). The proportion of the total health budget for mental health is $5.1 \%$, which is low when compared with, for instance, the UK (England and Wales 13.8\%, Scotland 9.5\%) (World Health Organization, 2008, p. 118, Fig. 8.1).

Hungary has long been a major contributor to the development of psychiatry, psychology and psychotherapy, through the works of Sándor Ferenczi, Géza Róheim, Melanie Klein, Michael Bálint, Lipót Szondi, Ferenc Mérei, Iván BöszörményiNagy, Kálmán Pándy, László von Meduna, Pál Juhász, Mihály Arató and the recently deceased István Degrell (Bánki, 1991; Rihmer \& Füredi, 1993).
\end{abstract}

\section{Status of general and mental health in Hungary}

The average life expectancy for a Hungarian citizen at birth is only 73.3 years, more than 5 years below the OECD average of 79 years. The mortality rate presently exceeds the birth rate, which means the population is declining. More than half the mortality is due to cardiovascular disease (coronary heart disease is the leading cause of death). As elsewhere, drinking, smoking, obesity, unhealthy eating habits and lack of physical activity undermine the health of the population (Skrabski et al, 2005; Tringer, 2005).

The prevalence of both mental disorders and substance use disorders is on the rise. About 300000-400000 people (around $4 \%$ of the population) experience depression, but only 40000 of them have a medical diagnosis (European Commission, 2008). A study applying DSM-IV criteria found the current rate for depression to be $18.5 \%$ among people attending primary care, while the rate for major depressive episode was $7.3 \%$ (Torzsa et al, 2008).

The suicide rate in Hungary remains the highest (after Lithuania) in the EU despite the fact that between 2000 and 2005 the decrease in Hungary's suicide rate was the second 